\title{
A função da filosofia na escola e seu caráter interdisciplinar
}

\author{
Sílvio Gallo \\ Universidade Estadual de Campinas \\ Universidade Metodista de Piracicaba \\ Universidade do Sagrado Coração
}

\section{A presença da filosofia na educação brasileira: panorama geral}

Na universidade brasileira hoje, não vemos a presença da filosofia nos currículos dos cursos, a não ser no caso de instituições confessionais, que entendem que conhecimentos de filosofia são necessários para a realização de seu projeto pedagógico.

Nas universidades públicas, a presença da filosofia nos cursos dá-se apenas quando é diretamente relacionada com aquela carreira.

No caso do ensino médio, a Lei de Diretrizes e Bases da Educação determina que o estudante deve dominar os "conhecimentos de filosofia necessários ao exercício da cidadania". Porém, não fica definido como tais conteúdos devam ser trabalhados.

No ensino fundamental, são apresentados, por exemplo, conteúdos de ética, a serem explorados como um "tema transversal" às disciplinas do currículo.

Historicamente, a filosofia chega ao sistema educacional brasileiro com os jesuítas, ainda no século dezesseis. Nesse momento, seu ensino tinha um forte caráter dogmático, impregnado de ideologia tomista. Com o advento da república e a hegemonia da ideologia positivista, a filosofia perde importância nos currículos da educação média, ficando centrada na lógica e na epistemologia. Na reforma educacional promovida pelo regime militar, a filosofia foi excluída dos currículos da educação média, permanecendo apenas como disciplina da "parte diversificada", em muitas escolas confessionais, sobretudo as católicas. Em meados dos anos oitenta, após muita luta e discussão, vimos o início de um retorno da filosofia ao currículo do ensino médio, com situações muito diferenciadas em cada estado da federação. No caso de São Paulo, por exemplo, esse retorno deu-se na forma de uma "disciplina optativa", que deveria ser incluída ou não pela direção de cada escola, escolhendo duas disciplinas entre filosofia, sociologia e psicologia, em pelo menos uma série do então segundo grau.

Esse movimento pela volta da filosofia ao ensino médio buscou expressão durante a redação da Lei de Diretrizes e Bases da Educação Nacional, mas a letra da lei acabou gerando uma situação que afirma e não afirma a filosofia ao mesmo tempo, ao evidenciar sua importância, mas não determiná-la como disciplina do 
currículo. É curioso que a partir de 1996, com a promulgação da LDB e o aparecimento e divulgação dos Parâmetros Curriculares Nacionais para os ensino fundamental e médio, o discurso em torno da importância da filosofia cresce, embora a prática efetiva das escolas não reflita esse crescimento.

\section{Por que filosofia no ensino médio?}

Quando pensamos na educação como amplo processo de formação humana e sobretudo no ensino médio, como um nível propedêutico à universidade ou então como etapa final da formação de um grande número de jovens que não vão para o ensino superior, podemos falar em três grandes áreas do conhecimento humano fundamentais, que devem estar presentes nessa formação: as ciências, as artes e as filosofias.

Partindo daquilo que Deleuze e Guattari produziram em O que é a filosofia? (Rio de Janeiro: Ed. 34, 1992), podemos dizer que as ciências, na sua relação com o mundo, produzem funções, que organizam os fatos observados através de relações de causa-efeito; as artes, por sua vez, produzem perceptos e afetos, formas de compreensão do mundo numa perspectiva estética; as filosofias, por fim, produzem conceitos, uma forma racional de equacionamento dos problemas vividos no mundo. Cada uma dessas formas de conhecimento humano, portanto, é irredutível à outra e são todas mutuamente complementares. Dizendo de outro modo, nenhuma ciência é capaz de fazer por mim aquilo que a filosofia faz, assim como nenhuma filosofia pode substituir os afetos estéticos, por exemplo. O que equivale a dizer que, se procuramos um processo educativo como formação humana, minimamente precisamos garantir a todos os estudantes o acesso a estas três instâncias de produção de saberes sobre o mundo.

Penso que reside aí a justificativa para a necessidade da presença da filosofia nos currículos do ensino médio. As diversas ciências lá estão; a experiência estética ou artística, de um outro modo também (na verdade, penso que deveríamos ter muito mais arte nos currículos, mas ao menos já temos alguma coisa). Mas e quanto às filosofias? Os estudantes têm acesso às funções científicas, aos perceptos e afetos artísticos, mas e aos conceitos filosóficos? Sem eles, não teremos um conhecimento abrangente, uma formação abrangente.

Repito: não penso que a filosofia se justifique nos currículos da educação média por promover uma forma de visão crítica do mundo (outras disciplinas também podem e devem fazer isso), nem por possibilitar uma visão interdisciplinar (outras disciplinas também podem e devem fazer isso), muito menos por trabalhar com conhecimentos fundamentais ao exercício da cidadania (no limite, a ação cidadã não reside na filosofia, mas talvez mesmo longe dela). Por outro lado, a ausência da filosofia nos currículos significa o não contato dos estudantes com essa importante construção humana, que é o conceito. Isso, sim, a filosofia pode oferecer. E apenas ela pode oferecer.

\section{A especificidade da filosofia e seu ensino}


Vejo como três as características básicas da filosofia: o pensamento conceitual; o caráter dialógico; a crítica radical. A experiência filosófica passa necessariamente por estas três instâncias. Mas aquilo que faz com que a filosofia seja filosofia, penso, na esteira de Deleuze e Guattari, é seu trabalho com o conceito; mais precisamente, seu trabalho de criação de conceitos. Escreveram eles que

O filósofo é o amigo do conceito, ele é conceito em potência. Quer dizer que a filosofia não é uma simples arte de formar, de inventar ou de fabricar conceitos, pois os conceitos não são necessariamente formas, achados ou produtos. A filosofia, mais rigorosamente, é a disciplina que consiste em criar conceitos /.../ Criar conceitos sempre novos, é o objeto da filosofia. É porque o conceito precisa ser criado que ele remete ao filósofo como aquele que o tem em potência, ou que tem sua potência e sua competência /.../ Os conceitos não nos esperam inteiramente feitos, como corpos celestes. Não há céu para os conceitos. Eles devem ser inventados, fabricados ou antes criados, e não seriam nada sem a assinatura daqueles que os criam /.../ Que valeria um filósofo do qual se pudesse dizer: ele não criou um conceito, ele não criou seus conceitos? (DELEUZE $e$ GUATTARI, 1992: 13-14)

Se a filosofia consiste na atividade de criar conceitos, que é isso então que ela cria? Podemos dizer que o conceito é uma forma eminentemente racional de equacionar um problema ou conjunto de problemas, exprimindo com isso uma visão coerente do vivido. Sendo assim, o conceito não é abstrato nem transcendente, mas imanente, uma vez que parte necessariamente de problemas experimentados, isto é, na medida em que não se cria conceito no vazio.

Se o conceito é o específico da filosofia, penso ser inconcebível uma aula de filosofia que não passe pelo trato com conceitos. Mas como lidar com os conceitos? Devemos fazer da aula de filosofia uma exposição de conceitos, um desfile de conceitos? A meu ver, uma aula de filosofia que não lide com conceitos não pode ser uma aula de filosofia; mas tampouco uma aula de filosofia que trate os conceitos como peças de museu, como algo já dado, tem algo de filosófica. Se a filosofia consiste na atividade de criar conceitos, a aula de filosofia é aquela que pratica essa atividade.

Gosto de pensar a aula de filosofia como uma oficina de conceitos, um local onde os conceitos historicamente criados são experimentados, testados, desmontados, remontados, sempre frente a nossos problemas vividos. E também um local onde se arrisque a criação de novos conceitos, por mais circunscritos e limitados que eles possam ser.

É o conceito que permite à filosofia que seja dialógica: dialogamos, sim, mas a partir de conceitos, ou o que dá no mesmo, com a filosofia promovemos o diálogo dos conceitos; assim como é o conceito que permite que ela produza uma crítica radical: criticamos, mas criticamos a partir do conceito e pelo conceito.

\section{Filosofia e transversalidade}


O conceito não é paradigmático, mas sintagmático; não é projetivo, mas conectivo; não é hierárquico, mas vicinal; não é referente, mas consistente. É forçoso, daí, que a filosofia, a ciência e a arte não se organizem mais como os níveis de uma mesma projeção e, mesmo, que não se diferenciem a partir de uma matriz comum, mas se coloquem ou se reconstituam imediatamente numa independência respectiva, uma divisão do trabalho que suscita entre elas relações de conexão. (DELEUZE e GUATTARI, 1992: 119-120)

Uma característica intrínseca da filosofia é a transversalidade, uma vez que o conceito é sintagmático, conectivo, vicinal, consistente. O que faz dele necessariamente um empreendimento de abertura e de relação. A filosofia não se fecha em si mesma, ensimesmada, mas abre-se sempre a outrem, busca a relação.

Não gosto de pensar a filosofia como um empreendimento interdisciplinar, pois isso me cheira a um positivismo démodé. Lembremos que Comte, não vendo a possibilidade da filosofia produzir verdades positivas, uma vez que não opera pela experimentação, como as ciências, reservou a ela a função interdisciplinar de reunir os conhecimentos parciais produzidos por cada ciência numa visão de conjunto, numa cosmovisão. Mas, por outro lado, não consigo deixar de vê-la como empreendimento transversal, que atravessa outros campos de saberes, na mesma medida em que é atravessada por eles. Penso que hoje não se cria conceito, não se produz filosofia, sem uma conexão direta e transversal com as diversas artes e as distintas ciências. Embora elas sejam distintas entre si, elas se retro-alimentam, se fecundam mutuamente.

No contexto de um currículo disciplinar, porém, não consigo ver como a filosofia seria tratada como um "tema transversal". Ela é transversal em sua criação, uma vez que atravessa outros campos e se deixa atravessar por eles; ela pode ser transversal em seu ensino, na medida em que o trabalho com o conceito pode e deve atravessar funçóes das diversas disciplinas científicas, perceptos e afetos das diferentes expressões artísticas, da mesma forma que é atravessado por essas outras potências criativas.

No entanto, a filosofia só pode ser transversal e/ou transversalizada se houver, efetivamente, o trato com o conceito. Mas como tratar do conceito num currículo loteado pelas disciplinas científicas com apenas pequenos e restritos guetos para as atividades artísticas e para as atividades físicas?

Trataremos do conceito em aulas de matemática? Ou de Física? Ou de História? Ou de Português? Não, nenhuma dessas disciplinas se presta ao trato com o conceito, entidade eminentemente filosófica, como vimos. Trataremos do conceito em aulas de Educação Artística? Ou de Educação Física? Também elas não se prestam a isso.

Podemos pensar a filosofia como um "tema transversal", mas num currículo que seja todo ele transversal, num currículo não disciplinar. Num currículo disciplinar em que o território é todo loteado e dividido entre as disciplinas, que se tornam verdadeiras "capitanias hereditárias", só podemos garantir a presença e a ação 
conceitual da filosofia se for, ela mesma, mais uma dessas capitanias, mais uma disciplina. Apenas a partir do momento em que se fixa um espaço para a filosofia nesse território loteado é que podemos assegurar o trabalho do conceito e almejar a transversalização dos saberes, num processo educativo minimamente abrangente.

\section{Bibliografia}

COMTE-SPONVILLE, André. Uma Educação Filosófica. São Paulo: Ed. Martins Fontes, 2001.

COSSUTTA, Frédéric. Elementos para a leitura de textos filosóficos. São Paulo: Ed. Martins Fontes, 1994.

DELEUZE, Gilles e GUATTARI, Félix. O que é a Filosofia? Rio de Janeiro: Ed. 34, 1992.

DELEUZE, Gilles. Conversações. Rio de Janeiro: Ed. 34, 1992.

DELEUZE, Gilles. Diferença e Repetição. Lisboa: Ed. Relógio D'Água, 2000.

FOUCAULT, Michel. O que é um filósofo?, in Ditos e Escritos II. Rio de Janeiro: Ed. Forense Universitária, 2000.

GALLO, Sílvio e KOHAN, Walter (orgs.). Filosofia no Ensino Médio. Petrópolis: Ed. Vozes, 2000.

GALLO, Sílvio; CORNELLI, Gabriele; DANELON, Márcio (orgs.). Filosofia do Ensino de Filosofia. Petrópolis: Ed. Vozes, 2003.

NIETZSCHE, Friedrich. Ecce Homo. SP: Ed. Cia. das Letras, 1995.

ONFRAY, Michel. A Política do Rebelde - tratado de resistência e de insubmissão. Rio de Janeiro: Ed. Rocco, 2001.

SAVATER, Fernando. As Perguntas da Vida. São Paulo: Ed. Martins Fontes, 2001.

SAVATER, Fernando. O Meu Dicionário Filosófico. Lisboa: Ed. Dom Quixote, 2000. 